Open J. Chem., Vol. 1(2018), Issue 1, pp. 19-25

Website: https://pisrt.org/psr-press/journals/ojc/

ISSN: 2618-0758 (online) 2618-074X (Print)

http://dx.doi.org/10.30538/psrp-ojc2018.0003

\title{
DIFFERENT APPROACHES FOR THE SYNTHESIS OF ZINC OXIDE NANOPARTICLES
}

\author{
ZAHEER AHMAD, FARMAN ULLAHKHA, SAJID MAHMOOD ${ }^{1}$, TARIQ MAHMOOD, \\ AISHA SHAMIM
}

\begin{abstract}
In this work we have described the synthesis of Zinc Oxide nanoparticles through chemical and biological methods. For biological synthesis Aspargillus niger was used. The product obtained was characterized through different analytical techniques like XRD, SEM and EDX. The obtained results were matched with the literature. It was confirmed that the Zinc Oxide nanoparticles can also be prepared from Aspargillus niger.Which may be more ecofriendly and economical compared to other commonly used methods.
\end{abstract}

Key words and phrases: Nanotechnology; Zinc oxide nanoparticles; Nanoparticles; Aspargillusniger; Biological synthesis.

\section{Introduction}

The nanotechnology is an area of intense scientific research in which nanomaterials are synthesized, characterized and applied. Nanoparticles are the clusters of atoms, ions or molecules who's size range is i $100 \mathrm{~nm}$. These include fullerenes, metal clusters, proteins etc. Many nanomaterial are formed by metals like Cobalt (Co), Copper (Cu), Zinc ( $\mathrm{Zn})$, Magnesium (Mg), Titanium (Ti), Gold ( $\mathrm{Au})$ and Silver $(\mathrm{Ag})$. Metal oxides nanoparticles can be prepared easily.Due to their small size they differ from the bulk materials. The nanoparticles are being used for different purposes i.e. for medical treatments, in different branches of industry productions such as solar and oxide fuel batteries for energy storage, for incorporation into various materials of daily use e.g. cosmetics or clothes. The Zinc

\footnotetext{
Received 09-7-2018. Revised 12-10-2018. Accepted 02-11-2018

1 Corresponding Author

(C) 2018 Zaheer Ahmad, Farman UllahKha, Sajid Mahmood, Tariq Mahmood, Aisha Shamim. This is an open access article distributed under the Creative Commons Attribution License, which permits unrestricted use, distribution, and reproduction in any medium, provided the original work is properly cited.
} 
oxide $(\mathrm{ZnO})$ nanoparticles has been widely used in the light emitting diodes, solar cells, piezoelectric transducers, gas sensors and as catalysts for long time. $\mathrm{ZnO}$ is one of the n-type semiconductor which have bandgap of about $3.37 \mathrm{ev}$ and has been used in different fields of catalysis, sensors, electronic devices, solar cells. As the $\mathrm{ZnO}$ nanoparticles have smaller size so they have large surface area. They have been synthesized by different methods so far. In 2010, they were synthesized from aqueous solutions in the form of equiaxed nanoparticles [1].They show some photocatalytic properties and are widely used in sunscreen cosmetics, clothes and also for the degradation of environmental pollutants. They have some biological activities also. In 2012, the antitumor activity of the photostimulated $\mathrm{ZnO}$ nanoparticles was studied. They were used with cisplatin and the results showed the increased antitumor activity [2]. In 2013, $\mathrm{ZnO}$ nanoparticles were also synthesized by using supercritical methanol in good yield [3]. They can be synthesized with combination of transition metals e.g. through the electrolysis process in which Zinc plate is used as anode in sodium tungstate solution [4].They are very effective against UV blocking and for in vivo toxicity of the polymer coated. The ZnO nanoparticles coated with chitosan (ZnO-CTS) and

polyethylene glycol (PEG) which is a synthetic polymer (ZnO-PEG) have also been synthesized and their photocatalytic activity was studied which showed the increased photocatalytic activity and stability and which also showed the better ultraviolet absorption efficiency [5].They can also be produced through hydrothermal method in which microwave is used. In this process by changing in the power and the time for microwave irradiation cause different morphological effects on the $\mathrm{ZnO}$ nanoparticles [6]. The $\mathrm{ZnO}$ nanoparticles were observed to cause eosinophilc airway inflammation in mice [7].

\section{Method and materials}

2.1. Materials. Zinc Chloride $(\mathrm{ZnCl} 2)$, Sodium Hydroxide $(\mathrm{NaOH})$. All these chemicals were of AR grade and purchased from Sigma Aldrich.

2.2. Procedure. We took $5 \mathrm{~g}$ of Zinc Chloride $(\mathrm{ZnCl} 2)$ and dissolved in small amount of distilled water to make its solution. This Solution was titrated with 0.5M Sodium Hydroxide $(\mathrm{NaOH})$ solution unless white precipitate appeared. Water was added in this precipitate and then washed with distilled water 5 times. This precipitate was filtered. The precipitate was separated and then put it in hot air oven at a temperature of $1050 \mathrm{C}$ for 3 hours. Then it was grind with mortar and pestle for 15 minutes and then put it in muffle furnace at $300 \mathrm{C}$ for 5 hours for calcination. After calcination its color changed to cream yellow from white. Then was grind again and stored in glass bottle for further process.

\section{Biological synthesis of Zno nanoparticles}

3.1. Materials. Zinc chloride $(\mathrm{ZnCl} 2)$, Sodium hydroxide $(\mathrm{NaOH})$, Deionized water, Aspargillus niger. All the chemicals were of AR grade and purchased from Sigma Aldrich. 
3.2. Procedure. In this method first of all salt solution was prepared by dissolving $5 \mathrm{~g}$ of salt in deionized water and mixed with $2 \mathrm{~g}$ crushed powder of Aspargillus niger and stirred for 30 minutes. Then the resultant material was placed in dark for 3 days. After 3 days the solution was filtered. The pale white filtrate was obtained. This filtrate was dried in hot air oven at $105 \mathrm{C}$ and then calcined in muffle furnace at $550 \mathrm{C}$ for 3 hours. The material was grind and stored for further analysis.

\section{Results and discussion}

For the characterization of prepared Zinc Oxide nanoparticles, XRD is one of the best technique. It characterizes the purity and phase of the nanomaterial. XRD gives detail of diffraction angle, the interlayer spacing and mainly the crystallite size. The XRD used in our work was Bruker D8 advance.Figure. 1 shows the XRD pattern of zinc oxide through chemical method. The peaks at $2 \theta=32.0$, $34.5,36.0,47.5,56.0,63.0,67.0,68.0$ and 69.0 which correspond to (100), (002), (101), (102), (110), (103), (200), (112) and (201) crystalline planes of $\mathrm{ZnO}$ and were in good agreement with the JCPDS Card no. 01-079-2205. All these peaks exactly match with the literature $[8,9]$ which clearly indicates the formation of zinc oxide. The average crystallite size of $\mathrm{ZnO} N$ P's was $71.5 \mathrm{~nm}$, calculated using Scherrer equation based on the full width at half-maximum of the (101) diffraction plane

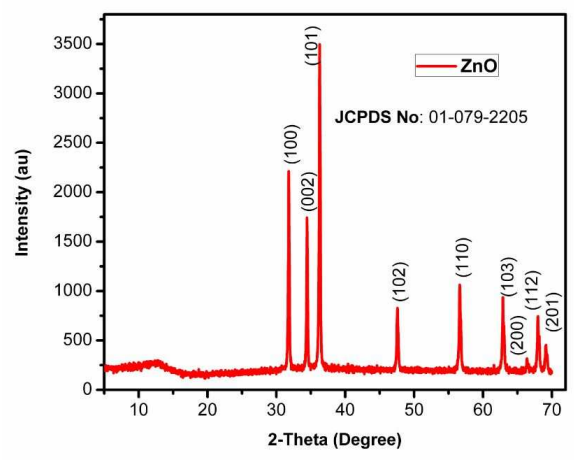

Figure 1.XRD pattern of Zinc Oxide NP (chemical method)

The XRD pattern of biologically synthesized Zinc Oxide nanoparticles is shown in Figure 2. The peaks at 2 position of $31.76,34.42,36.25,47.53,56.60,62.86$, $66.37,67.96$ and 69.09 represent the $\mathrm{ZnO}$ nanoparticles of crystallite size of 40.8 nm size successfully prepared through biological method. 


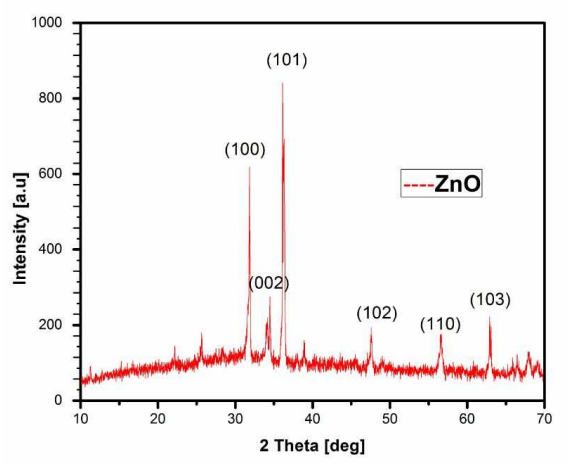

Figure 2. XRD pattern of Zinc Oxide NP (biological method)

Then Zinc Oxide nanoparticleswere characterized by the Scanning Electron Microscopy (SEM) for their surface morphology. The SEM used in this experiment was FEI Quanta 450 FEG. Fig.3 shows FESEM images of Zinc Oxide nanoparticles at different magnifications. The particles are agglomerated. The particles are not enough separated which show the presence of weak physical forces. The results were also matched with the earlier studies $[10,11]$.
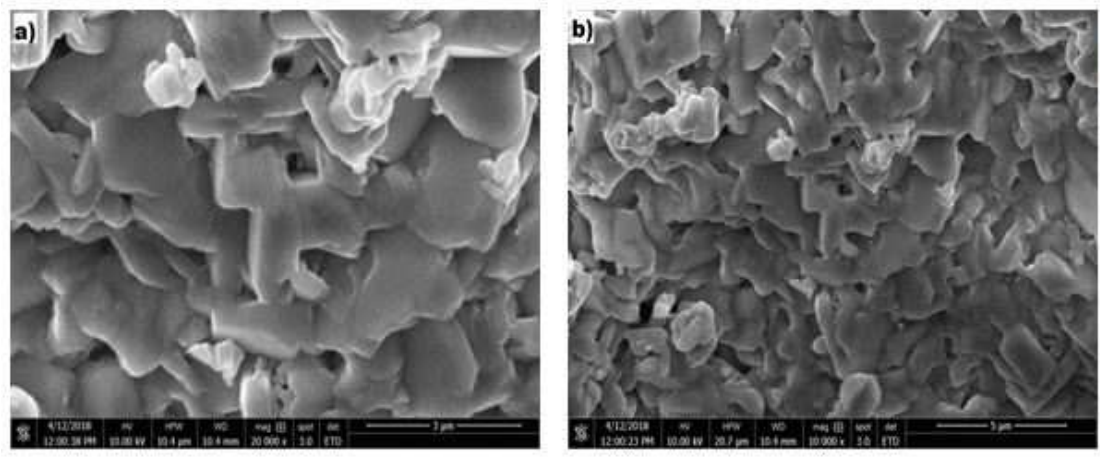

Figure 3. SEM images of $\mathrm{ZnO} \mathrm{NP}$ (chemical method)

The Zinc Oxide nanoparticles synthesized through biological methods were characterized through SEM, TESCAN, VEGA3. The SEM images of biologically synthesized nanoparticles are shown in Figure 4. Which also show the spherical and agglomerated $\mathrm{ZnO}$ nanoparticles formation. 


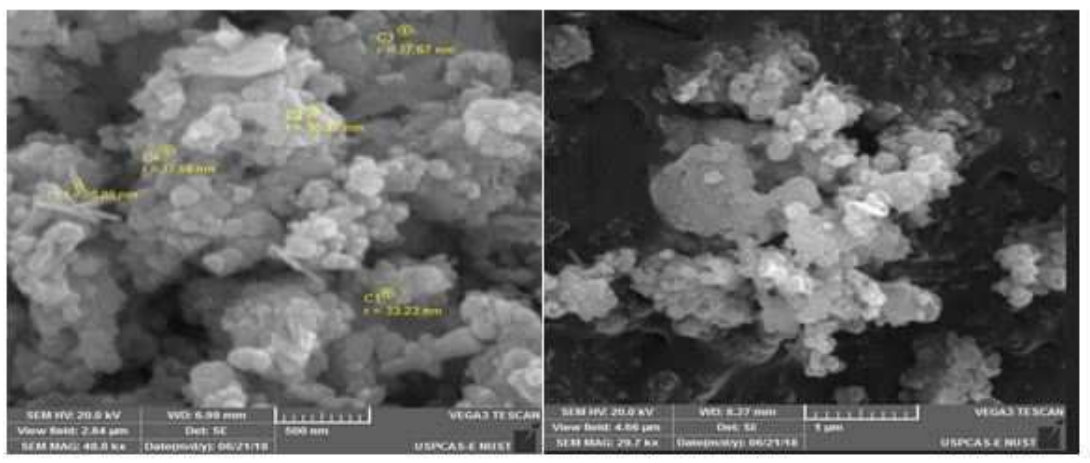

Figure 4. SEM images of ZnO NP (biological method)

The Elemental analysis was carried out through EDX. Figure.5 shows the EDX spectra of Zinc Oxide nanoparticles prepared from chemical method.This shows the highest weight \% of 57.03 for $\mathrm{Zn}$ which clearly shows the formation of $\mathrm{ZnO}$ nanoparticles.

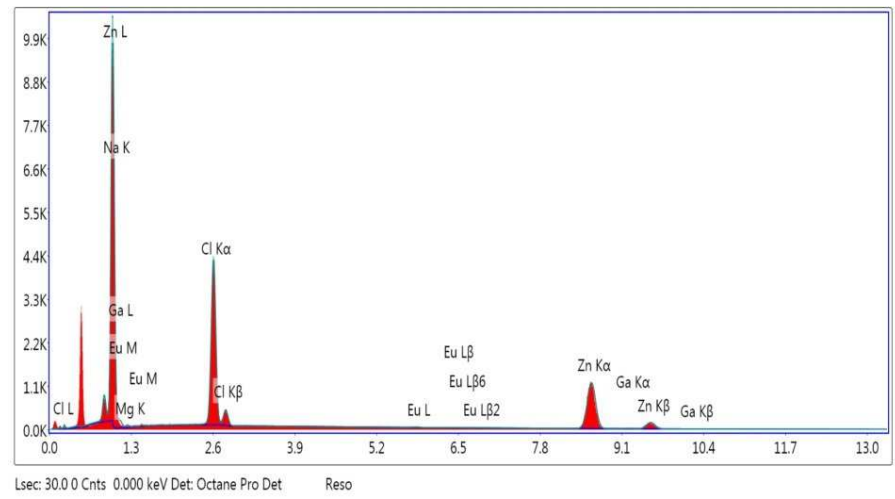

Figure 5. EDX spectra of ZnO NP (chemical method)

The elemental analysis of biologically synthesized Zinc Oxide nanoparticles was performed on EDX Oxford. Figure.6 shows the EDX spectra of Zinc Oxide nanoparticles prepared from biological method. In this case the Zn weight \% is 85.9 while oxygen $8.6 \%$. Which is clear indication of formation of the Zinc Oxide nanoparticles. 


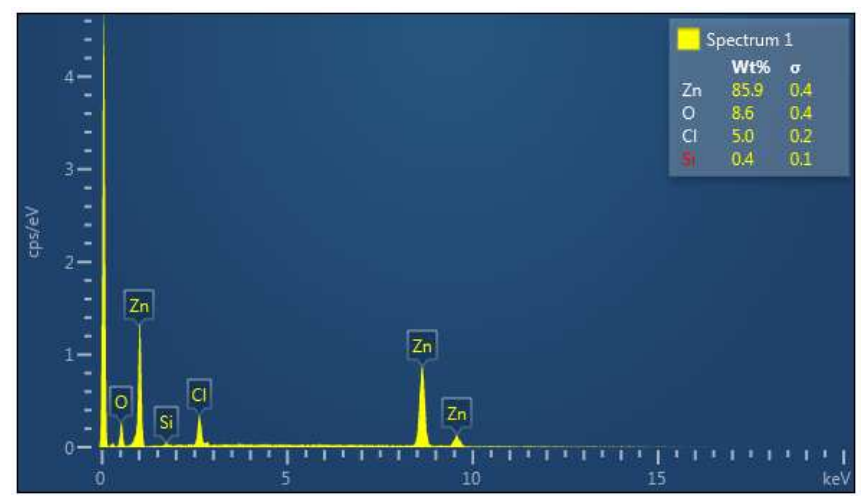

Figure 5. EDX Spectra of ZnO NP (biological method)

\section{Conclusion}

In summary, The Zinc Oxide nanoparticles were successfully synthesized by two different methods i.e. chemical and biological. For biological synthesis Aspargillus niger was used. The product obtained was characterized through different analytical techniques like XRD, SEM and EDX. The obtained results weretallied with literature. It was revealed that the $\mathrm{ZnO}$ nanoparticles can be prepared from Aspargillus niger in sufficient quantity with high purity.

\section{Acknowledgement}

This work was impossible without the help and guidelines of my supervisor Dr. Zaheer Ahmad, Chemistry Department University of Wah, Wah Cantt and cosupervisor Dr. Tariq Mahmood, NCP, Islamabad. I cordially thank them for their support and guidance throughout this research work.

\section{Competing Interests}

The author do not have any competing interests in the manuscript.

\section{REFERENCES}

1. Lu, K., \& Zhao, J. (2010). Equiaxed zinc oxide nanoparticle synthesis. Chemical Engineering Journal, 160(2), 788-793.

2. Hackenberg, S., Scherzed, A., Harnisch, W., Froelich, K., Ginzkey, C., Koehler, C., ... \& Kleinsasser, N. (2012). Antitumor activity of photo-stimulated zinc oxide nanoparticles combined with paclitaxel or cisplatin in HNSCC cell lines. Journal of Photochemistry and Photobiology B: Biology, 114, 87-93.

3. Kim, M., Lee, H. S., Yoo, S. J., Youn, Y. S., Shin, Y. H., \& Lee, Y. W. (2013). Simultaneous synthesis of biodiesel and zinc oxide nanoparticles using supercritical methanol. Fuel, 109, 279-284.

4. Rahimi-Nasrabadi, M., Pourmortazavi, S. M., Ganjali, M. R., Hajimirsadeghi, S. S., \& Zahedi, M. M. (2013). Electrosynthesis and characterization of zinc tungstate nanoparticles. Journal of Molecular Structure, 1047, 31-36. 
5. Girigoswami, K., Viswanathan, M., Murugesan, R., \& Girigoswami, A. (2015). Studies on polymer-coated zinc oxide nanoparticles: UV-blocking efficacy and in vivo toxicity. Materials Science and Engineering: C, 56, 501-510.

6. Hasanpoor, M., Aliofkhazraei, M., \& Delavari, H. (2015). Microwave-assisted synthesis of zinc oxide nanoparticles. Procedia Materials Science, 11, 320-325.

7. Huang, K. L., Lee, Y. H., Chen, H. I., Liao, H. S., Chiang, B. L., \& Cheng, T. J. (2015). Zinc oxide nanoparticles induce eosinophilic airway inflammation in mice. Journal of hazardous materials, 297, 304-312.

8. Akhtar, M. J., Ahamed, M., Kumar, S., Khan, M. M., Ahmad, J., \& Alrokayan, S. A. (2012). Zinc oxide nanoparticles selectively induce apoptosis in human cancer cells through reactive oxygen species. International journal of nanomedicine, 7,845 .

9. Hosseini, S. A., \& Babaei, S. (2017). Graphene oxide/zinc oxide (GO/ZnO) nanocomposite as a superior photocatalyst for degradation of methylene blue (MB)-process modeling by response surface methodology (RSM). Journal of the Brazilian Chemical Society, 28(2), 299-307.

10. Mohan, A. C., \& Renjanadevi, B. (2016). Preparation of zinc oxide nanoparticles and its characterization using scanning electron microscopy (SEM) and X-ray diffraction (XRD). Procedia Technology, 24, 761-766.

11. Geetha, A., Sakthivel, R., Mallika, J., Kannusamy, R., \& Rajendran, R. (2016). Green Synthesis of antibacterial Zinc oxide Nanoparticles using biopolymer Azadirachtaindica gum. Oriental Journal of Chemistry, 32(2), 955-963.

Zaheer Ahmad

Department of Chemistry, University of Wah, Wah Cantt, 47040 -Pakistan.

Farman UllahKha

Department of Chemistry, Division of Science and Technology, University of Education, Lahore Pakistan.

Sajid Mahmood

Department of Chemistry, Division of Science and Technology, University of Education, Lahore Pakistan.

e-mail:drsajidue@gmail.com

Tariq Mahmood

Nano Science and Technology Department, National Centre for Physics, Quaid-e-Azam University, Islamabad 45320-Pakistan.

Farman Ullah Khan

Department of Chemistry, University of Wah, Wah Cantt, 47040 -Pakistan. 